\title{
A Case of Intractable Otitis Media: Eosinophilic Otitis Media
}

\author{
Mehmet Turgay Türkmen, Recep Yağız
}

Department of Otolaryngology, Trakya University Faculty of Medicine, Edirne, Turkey

\section{Dear Editor,}

The term eosinophilic otitis media (EOM) was first used by Tomioka et al. (1) to describe bronchial asthma-related, treatment-resistant, eosinophil-enriched cases with viscous middle ear effusion. Diagnostic criteria for EOM were established after a multicentre analysis conducted in Japan in 2011. The major criterion is otitis media with effusion or chronic otitis media with eosinophil-dominant effusion. Minor criteria include: bronchial asthma, nasal polyp, viscous middle ear effusion, and otitis media resistant to conventional therapies. The diagnosis requires a combination of two or more minor criteria and the major criterion (2). A 47-year-old female presented with hearing loss. She had received medical therapy for otitis media with effusion for seven months; however, her hearing loss did not regress. The patient had received asthma treatments during the previous four years. An audiological examination showed that the patient had moderate conductive hearing loss in her left ear. A ventilation tube was administered upon the diagnosis of chronic otitis media with effusion in her left ear. Four months after tube administration the hearing loss problem of the patient had not regressed; furthermore, a yellowish dense discharge in the left ear was evaluated. A temporal computerized tomography (CT) used for detection of the mastoid cavity and the middle ear's soft tissue density was performed and, due to the prediagnosis of granular otitis media, a reoperation was planned. During the operation, it was observed that the middle ear ossicles were surrounded by dense edematous mucosa and polypoid tissues. A dense yellowish viscous fluid was found in the middle ear cavity and mastoid cells (Figure 1). A simple mastoidectomy and tympanoplasty were conducted and a ventilation tube was inserted into the left ear. Twelve months after the first operation, a ventilation tube was inserted into the right ear because moderate conductive hearing loss had become more prominent in both ears and chronic otitis media with effusion was identified. Due to ongoing otorrhea for 16 months after the first operation, the patient

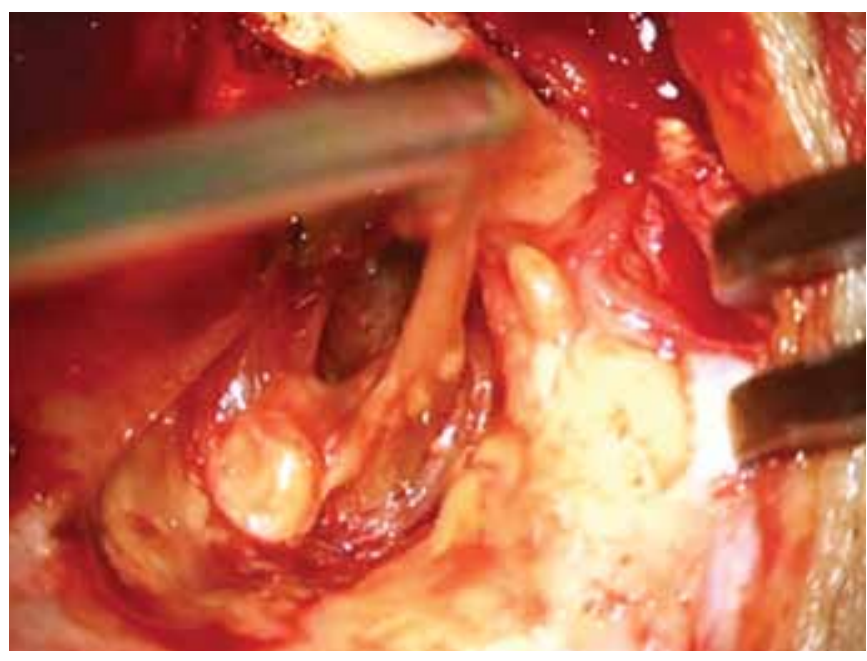

FIG. 1. Viscous yellow effusion from the middle ear cavity during mastoidectomy

was operated on again. During the postoperative period, otorrhea from the left ear remained. Local and systemic steroid therapies and oral antihistaminic therapy were attempted, but the effusion could not be controlled. The patient was receiving optimum asthma therapy during all the operations. Therefore, our patient with treatment-resistant otitis media with effusion was diagnosed with eosinophilic otitis media based on three minor criteria accompanied by the major criterion. Nearly all the clinical studies and case reports about EOM originate from the Far East, particularly Japan (2). The pathogenesis of EOM has not been fully explained (3). Although the middle ear is thought to be affected by the way of Eustachian tube in asthma patients, some studies showed that there was also an eosinophilic inflammatory component in the middle ear mucosa (4). Based on our literature search, ours is the first patient diagnosed with EOM reported in Turkey. We present this case to increase awareness of the disease and encourage the formation of larger patient groups in Turkey and the Balkans. 


\section{Ethics Committee Approval: N/A.}

Informed Consent: Written informed consent was obtained from the patient for the publication of this case report and any accompanying images.

Peer-review: Externally peer-reviewed.

Author contributions: Concept - M.T.T., R.Y.; Design - M.T.T., R.Y.; Supervision - M.T.T., R.Y.; Resource - M.T.T., R.Y.; Materials - M.T.T., R.Y.; Data Collection\&/or Processing - M.T.T., R.Y.; Analysis\&/or Interpretation M.T.T., R.Y.; Literature Search - M.T.T., R.Y.; Writing - M.T.T., R.Y; Critical Reviews - M.T.T., R.Y.

Conflict of Interest: No conflict of interest was declared by the authors.

Financial Disclosure: The authors declared that this report has received no financial support.

\section{REFERENCES}

1. Tomioka S, Kobayashi T, Takasaka T. Intractable otitis media in patients with bronchial asthma (eosinophilic otitis media). In: Sanna M, editor. Cholesteatoma and mastoid surgery. Rome: CIC Edizioni Internazionali; 1997:851-3.

2. Iino Y, Matsutani ST, Matsubara A, Nakagawa T, Nonaka M. Diagnostic criteria of eosinophilic otitis media, a newly recognized middle ear disease. Auris Nasus Larynx 2011;38:456-61. [CrossRef]

3. Wada T, Uemaetomari I, Murashita H, Tobita T, Tsuji S, Tabuchi K, et al. Successful treatment of eosinophilic otitis media using ramatroban: Report of two cases. Auris Nasus Larynx 2006;33:455-60. [CrossRef]

4. Iino Y, Nagamine H, Yabe T, Matsutani S. Eosinophils are activated in middle ear mucosa and middle ear effusion of patients with intractable otitis media associated with bronchial asthma. Clin Exp Allergy 2001;31:1135-43. [CrossRef] 